\title{
Mechanical, technical, and biological complications of dental implants
}

\author{
Meisan Ali Bukhari ${ }^{1 *}$, Nada Ghurmallah Almalki², Abdullah Mohammed Alkhudhayr ${ }^{3}$, \\ Sana Zaki Alburaiki ${ }^{4}$, Alya Zyad Aljumaiah ${ }^{5}$, Sawaher Khaleel Haddad ${ }^{6}$, \\ Heba Tariq Jan $^{7}$, Hamad Murayshid Alrowaithy ${ }^{8}$, Norah Ali Alqahtani', \\ Mohanned Majdi Toras ${ }^{10}$, Rayan Hussain Alwadei ${ }^{10}$
}

\author{
${ }^{1}$ North Jeddah Specialist Dental Center, King Abdullah Medical Complex, Jeddah, Saudi Arabia \\ ${ }^{2}$ General Dentist, Ministry of Health, Sakaka, Saudi Arabia \\ ${ }^{3}$ General Dentist, Ministry of Health, Khamis Mushait, Saudi Arabia \\ ${ }^{4}$ Dental Department, Qatif Central Hospital, Qatif, Saudi Arabia \\ ${ }^{5}$ General Dentist, Choueifat Clinic, Jeddah, Saudi Arabia \\ ${ }^{6}$ General Dentist, Al Arak Modern Dental and Orthodontic Clinics, Jeddah, Saudi Arabia \\ ${ }^{7}$ Dental Department, Haql General Hospital, Haql, Saudi Arabia \\ ${ }^{8}$ General Dentist, Qassim Regional Dental Center, Buraydah, Saudi Arabia \\ ${ }^{9}$ College of Dentistry, King Khalid University, Abha, Saudi Arabia \\ ${ }^{10}$ College of Dentistry, King Abdulaziz University, Jeddah, Saudi Arabia
}

Received: 14 December 2021

Accepted: 29 December 2021

\author{
*Correspondence: \\ Dr. Meisan Ali Bukhari, \\ E-mail: meisan-aml@gmail.com
}

Copyright: () the author(s), publisher and licensee Medip Academy. This is an open-access article distributed under the terms of the Creative Commons Attribution Non-Commercial License, which permits unrestricted non-commercial use, distribution, and reproduction in any medium, provided the original work is properly cited.

\begin{abstract}
Evidence indicates the effectiveness of these modalities in enhancing the quality of life for the affected patients. Furthermore, many previous investigations have assessed the survival rates of these modalities. Estimates show that implant-supported fixed partial dentures have survival rates of up to 10 years. However, it should be noted that many complications were reported following implantation procedures. These events can reduce the prognosis of the process and worsen the outcomes by decreasing the survival rate. The present literature review aims to provide evidence regarding dental implants' technical, biological, and mechanical complications. It should be noted that the incidence of these complications is generally decreasing based on the recent advance in the field. Adequate knowledge of the landmarks, careful treatment planning, proper case selection, obtaining a comprehensive history and information about implant procedure, and proper sterilization protocol are all different factors that can enhance the prognosis of the implant procedure. These can also reduce the frequency of the reported complications. Furthermore, these complications can be further reduced by being up to date with the recent advances and potential problem-solving research that usually provides adequate solutions that can reduce the frequency of these complications.
\end{abstract}

Keywords: Dental implant, Fixed partial dentures, Restoration, Complications

\section{INTRODUCTION}

Implants have been introduced to dentistry secondary to the increasing population's need to restore pleasing aesthetics after teeth loss. In this context, tooth extraction can be attributed to different reasons, including periodontal diseases and dental caries, with variable prevalence rates across different countries. ${ }^{1-3}$ In dental implantation, implant-supported fixed partial dentures and single crown implants are being widely used. Osseointegration is the basis upon which the whole process of implantation is built. $^{4,5}$ 
Evidence indicates the effectiveness of these modalities in enhancing the quality of life for the affected patients. Furthermore, many previous investigations have assessed the survival rates of these modalities. Estimates show that implant-supported fixed partial dentures have survival rates of up to 10 years. ${ }^{6-9}$ However, it should be noted that many complications were reported following implantation procedures. These events can reduce the prognosis of the process and worsen the outcomes by decreasing the survival rate. ${ }^{10,11}$ The present literature review aims to provide evidence regarding dental implants' technical, biological, and mechanical complications.

\section{METHODS}

This literature review is based on an extensive literature search in Medline, Cochrane, and EMBASE databases on which was performed $3^{\text {rd }}$ December 2021 using the Medical subject headings (MeSH) or a combination of all possible related terms, according to the database. To avoid missing poetential studies, a further manual search for papers was done through Google Scholar, while the reference lists of the initially included papers. Studies discussing mechanical, technical, and biological complications of dental implants were screened for useful information, with no limitations posed on date, language, age of participants, or publication type.

\section{DISCUSSION}

Different complications were reported in the literature secondary to the different types of dental implant procedures. In the current section, we have broadly divided these complications into technical, mechanical, and biological complications, which will be adequately discussed based on evidence from the relevant investigations in the literature.

\section{Technical complications}

Among the different types of dental implant complications, estimates show that technical ones are frequently encountered during this setting. Studies show that these complications are more frequent with implant-supported fixed partial dentures than with removable prostheses. ${ }^{12}$ Fracture complications are the most commonly encountered during these operations, including fracture of veneering porcelain and fracture of the framework. Different restoration materials are currently being reported in the literature with variable efficacies, and some studies said that metal-ceramic restorations are the most typical types used in this context. ${ }^{13,14}$ It should be furtherly noted that most clinicians and researchers usually focus on allceramic-based restorations based on the increasing needs of aesthetic functions of these modalities among patients. ${ }^{15}$ Studies reported that single-implant restorations could be complicated by veneering ceramic fractures, estimated to be a common event in these settings. ${ }^{16,17}$ This has been indicated in a previous follow-up investigation, which lasted for five years, by Sadid-Zadeh et al. ${ }^{18}$ The authors estimated that the rate of complications was $3.4 \%$ during the study period. A total of 172 failures were calculated (as a result of chopping off), among 5052 included porcelain and ceramic fused to metal restorations. On the other hand, it has been demonstrated that following the clinical recommendations can effectively reduce the incidence of these complications affecting veneering ceramic materials. These recommendations include providing sufficient thickness of the overlying ceramic, keeping shallow cuspal heights, reducing heavy occlusal contacts, and decreasing the occlusal table. Fractures to the framework were also evidenced in the literature as common technical complications that usually affect partially edentulous jaws. Positional stability of the transfer posts, impression techniques, and impression materials are the factors that can determine the accuracy of the framework. ${ }^{19-22}$ Therefore, researchers and dentists must target these events to enhance the management outcomes and reduce the prevalence of these complications.

\section{Biological complications}

Many investigations in the literature also reported different biological complications. These include sensory disruptions, progressive bone loss, microbial plaque formation, and bacterial infections. ${ }^{23-25}$ Studies furtherly demonstrated that these complications could be classified into early and late biological or implant failures. For example, failing to place the surgical implant within adequate aseptic approaches refers to premature failure complications..$^{23,26-29}$ On the other hand, periimplantitis and associated infections caused by dental plaques refer to late complications. In these settings, evidence shows that periimplantitis are more frequently encountered. Therefore, these should be cared for to enhance the management and prognosis of these cases. Peri-implantitis usually affects the surrounding hard and soft tissues of the osseointegrated implants by inflammation, leading to remarkable pathological changes. ${ }^{30}$ After successfully placing the implant, these pathological changes develop secondary to the increasing abnormal reactions between the underlying bacteria and host defense. The clinical manifestations of the condition do not usually develop rapidly as the pathology takes time to develop. ${ }^{31}$ An estimated five years until the patient complains about the development of related symptoms was reported. ${ }^{23,24,32}$ It should be noted that the incidence of periimplantitis in these conditions might be underestimated because the related investigations are not adequately lengthy with sufficient follow-up periods. Therefore, further studies with more extended follow-up periods are encouraged to estimate the true incidence of this complication. ${ }^{33}$

Intervening against the development of periimplantitis and spread to causative organisms is usually achieved by the sound dental and oral environment surrounding the implant. Breaching this biological barrier by any etiology can significantly lead to bacterial contamination around the area of implantation. This is remarkably associated with the sudden destruction of the different soft and hard tissues 
around the implanted material. ${ }^{34}$ Unequal occlusal load distribution might also add to the pathology of the condition and progression of periimplantitis. This occurs due to infections to the surrounding tissues and loosening of the related structures, cumulatively adding to the inflammatory process and boosting the pathology of the condition. ${ }^{35}$ Different factors were reported to predispose to these events, including many systemic diseases and conditions, which mainly suppress the immune response in the affected patients. These factors include the administration of chemotherapy, radiotherapy, uncontrolled periodontitis, long-term administration of steroids, smoking, osteoporosis, and uncontrolled diabetes mellitus. ${ }^{31,36,37}$

Among the different studies in the literature, we found various radiographic and clinical features that indicate the presence of periimplantitis. These include bleeding on suppuration or probing, potential hyperplasia and swelling around the implant region, bone or attachment loss of 2.5 $\mathrm{mm}$, probing depth $<6 \mathrm{~mm}$, radiographic vertical destruction of crestal bone. In addition, it has been reported that acute infection is present when pain or tenderness is reported on top of these manifestations. ${ }^{36,38}$ However, pain is not usually reported in normal circumstances. The presence of periimplantitis can progressively lead to implant treatment failure. ${ }^{33}$ Therefore, different prevention strategies were reported in the literature to prevent the development of the condition and adequately deal with it. Some of these strategies include surgical debridement of the affected tissues with bone grafting and the administration of antimicrobial modalities to eliminate periimplantitis and periodontitis. Moreover, non-surgical mechanical debridement was also reported in the literature. In cases when mobility is indicated following the diagnosis of peri-implantitis, or there is sufficient evidence indicating the presence of $60 \%$ of total bone loss, implant removal is suggested. ${ }^{34}$

\section{Mechanical complications}

Different mechanical complications were reported in the literature, and studies show that these events have variable frequencies. In addition, biomechanical overloading has been evidenced to be directly responsible for the development of these complications. ${ }^{39,40}$ Different factors were reported to contribute to biomechanical overloading. These factors include the presence of extensive forces secondary to parafunctional habits, available bone materials, or bruxism, in addition to missing posterior teeth or insufficient posterior support. Other factors include an apical or horizontal offset of the implant, implant inclination, and cuspal inclination, resulting from poor implant angulation or positioning. In addition, fractures or loosening of the implant materials has been reported to develop secondary to implant overloading. ${ }^{41-44}$ In this context, a previous investigation indicated that the prevalence of screw fractures or loosening was less frequent when abutment screws were used than prosthetic screws. ${ }^{45}$ Screw loosening was also less frequent with multiple restored units and implants than the estimated events with single crowns. ${ }^{46}$

Furthermore, it has been evidenced that screw loosening usually affects mandibular molar implant restorations compared to maxillary restorations. ${ }^{47}$ In a previous longterm investigation, which lasted for 15 years of follow-up, the authors reported that the prevalence of abutment or abutment screw loosening was $59.6 \%$ in their samples. ${ }^{48}$ Haas et al also conducted another follow-up investigation to find that screw loosening was the most frequently observed complication in the settings of Branemark singletooth implants. ${ }^{49}$ Pjetursson et al also conducted a systematic review and found that the prevalence of screw or abutment loosening was variable and ranged between $0.62 \%$ to $2.29 \%$ per year. ${ }^{50}$ The authors furtherly estimated that the five-year total complication rate for these events was $3.1 \%-10.8 \%$. Therefore, curtailing joint separating forces together with maximizing the clamping strengths of the joint is recommended to reduce the incidence of screw loosening. The reported joint separation forces include nonpassive frameworks, off-axis centric contacts, interproximal contacts, cantilevered contacts, and excursive contacts. Based on these factors and the incidence of screw loosening, the different implantation materials have been revised by manufacturers to decrease the incidence of these complications. ${ }^{8,26,31}$

Another complication of mechanical overloading includes cement failure, which usually impacts the prosthesis attachment. However, evidence indicates that recementation procedures can effectively manage these complications. In addition, it should be noted that recent investigations suggest that the incidence of these complications has significantly decreased as a result of the recent advances in the development of luting materials and material science. On the other hand, careful treatment approaches should be planned and applied in these settings to prevent associated complications and adverse events. $^{47,48}$ Peri-implant vertical bone loss is another mechanism that can eventually lead to implant fracture, together with biomechanical overloading. Studies show that when vertical bone loss is more severe than the limits of the apical screw, the incidence of implant fracture significantly increases. Factors related to the implant materials and the manufacturing process also contribute to implant fractures. Changes in the prosthesis design can also attribute to implant fractures secondary to recurrent and unnoticed screw loosening. Fractures of the hexagonal head are the most commonly reported sites of fractures to the implant screws away from the body. Extensive sideward loads are also reported to affect the loosened screws. ${ }^{12,34}$ This can reduce the efficiency and functions of the implant due to the reduced capabilities of the remaining materials and fragments following fractures of the implantabutment screw.

Reduced occlusal forces were reported to be more frequently associated with wearing an implant-supported prosthesis, whether removable or fixed. In addition, the 
incidence rates of implant fractures were reportedly correlated with the implant diameter. For instance, evidence shows that a diameter of $3.75-4 \mathrm{~mm}$ is at increased risk of fracture than other implants with larger diameters. In this context, it has been estimated that having a diameter of 5 and $6 \mathrm{~mm}$ is three and six times stronger than having a diameter of $3.75 \mathrm{~mm}$, respectively. ${ }^{11,45}$ Studies also reported that different factors could contribute to implant fractures, including aspects related to the implant components and prosthesis, in addition to periodontal factors. For example, implant factors include implant design, crown/implant $>1$, and diameter $<4 \mathrm{~mm}$, while prosthetic factors include cantilevers, prosthesis screws, ceramic fractures, and torsions or loosening. On the other hand, periodontal factors include bone loss, pocket depth $>5 \mathrm{~mm}$, and the presence of bruxism. Finally, it should be noted that specific strategies were reported to reduce the incidence of abutment screw loosening and fractures. These include tightening the implant to the recommended torque, understanding the occlusal scheme, carefully planning the appropriate management modality, and conducting regular follow-up points. ${ }^{48,50}$

\section{CONCLUSION}

It should be noted that the incidence of these complications is generally decreasing based on the recent advance in the field. Adequate knowledge of the landmarks, careful treatment planning, proper case selection, obtaining a comprehensive history and information about implant procedure, and proper sterilization protocol are all different factors that can enhance the prognosis of the implant procedure. These can also reduce the frequency of the reported complications. Furthermore, these complications can be further reduced by being up to date with the recent advances and potential problem-solving research that usually provides adequate solutions to reduce the frequency of these complications.

\section{Funding: No funding sources \\ Conflict of interest: None declared \\ Ethical approval: Not required}

\section{REFERENCES}

1. Reich E, Hiller KA. Reasons for tooth extraction in the western states of Germany. Community Dent Oral Epidemiol. 1993;21(6):379-83.

2. Angelillo IF, Nobile CG, Pavia M. Survey of reasons for extraction of permanent teeth in Italy. Community Dent Oral Epidemiol. 1996;24(5):336-40.

3. Murray H, Locker D, Kay EJ. Patterns of and reasons for tooth extractions in general dental practice in Ontario, Canada. Community Dent Oral Epidemiol. 1996;24(3):196-200.

4. Branemark PI. Tissue-integrated prostheses. Quintessence. 1985;99-115.

5. Chan RW, Tseng TN. Single tooth replacement-expanded treatment options. Aust Dent J. 1994;39(3):137-49.
6. Chan RW, Tseng TN. Single tooth replacement-expanded treatment options. Aust Dent J. 1994;39(3):137-49.

7. Henry PJ, Laney WR, Jemt T, Harris D, Krogh PH, Polizzi G, et al. Osseointegrated implants for singletooth replacement: a prospective 5-year multicenter study. Int $\mathrm{J}$ Oral Maxillofac Implants. 1996;11(4):450-5.

8. Jung RE, Pjetursson BE, Glauser R, Zembic A, Zwahlen M, Lang NP. A systematic review of the 5year survival and complication rates of implantsupported single crowns. Clin Oral Implants Res. 2008;19(2):119-30.

9. Pjetursson BE, Tan K, Lang NP, Brägger U, Egger M, Zwahlen M. A systematic review of the survival and complication rates of fixed partial dentures (FPDs) after an observation period of at least 5 years. Clin Oral Implants Res. 2004;15(6):625-42.

10. Hanif A, Qureshi S, Sheikh Z, Rashid H. Complications in implant dentistry. Eur J Dent. 2017;11(1):135-40.

11. Liaw K, Delfini RH, Abrahams JJ. Dental Implant Complications. Semin Ultrasound CT MR. 2015;36(5):427-33.

12. Jemt T. Failures and complications in 391 consecutively inserted fixed prostheses supported by Brånemark implants in edentulous jaws: a study of treatment from the time of prosthesis placement to the first annual checkup. Int J Oral Maxillofac Implants. 1991;6(3):270-6.

13. Hebel KS, Gajjar RC. Cement-retained versus screwretained implant restorations: achieving optimal occlusion and esthetics in implant dentistry. J Prosthet Dent. 1997;77(1):28-35.

14. Segal BS. Retrospective assessment of 546 allceramic anterior and posterior crowns in a general practice. J Prosthet Dent. 2001;85(6):544-50.

15. Ekfeldt A, Fürst B, Carlsson GE. Zirconia abutments for single-tooth implant restorations: a retrospective and clinical follow-up study. Clin Oral Implants Res. 2011;22(11):1308-14.

16. Vigolo P, Mutinelli S, Givani A, Stellini E. Cemented versus screw-retained implant-supported single-tooth crowns: a 10-year randomised controlled trial. Eur J Oral Implantol. 2012;5(4):355-64.

17. Sailer I, Mühlemann S, Zwahlen M, Hämmerle CH, Schneider D. Cemented and screw-retained implant reconstructions: a systematic review of the survival and complication rates. Clin Oral Implants Res. 2012;23(6):163-201.

18. Zadeh R, Kutkut A, Kim H. Prosthetic failure in implant dentistry. Dent Clin North Am. 2015;59(1):195-214.

19. Phillips KM. The accuracy of three implant impression techniques: A three-dimensional analysis. Int J Oral Maxillofacial Implant. 1994;9:533-40.

20. Assif D, Fenton A, Zarb G, Schmitt A. Comparative accuracy of implant impression procedures. Int $\mathbf{J}$ Periodontics Restorative Dent. 1992;12(2):112-21. 
21. Spector MR, Donovan TE, Nicholls JI. An evaluation of impression techniques for osseointegrated implants. J Prosthet Dent. 1990;63(4):444-7.

22. Humphries RM, Yaman P, Bloem TJ. The accuracy of implant master casts constructed from transfer impressions. Int $\mathbf{J}$ Oral Maxillofac Implants. 1990;5(4):331-6.

23. Quirynen M, Soete M, van Steenberghe D. Infectious risks for oral implants: a review of the literature. Clin Oral Implants Res. 2002;13(1):1-19.

24. Klinge B, Hultin M, Berglundh T. Peri-implantitis. Dent Clin North Am. 2005;49(3):661-76.

25. Berglundh T, Persson L, Klinge B. A systematic review of the incidence of biological and technical complications in implant dentistry reported in prospective longitudinal studies of at least 5 years. J Clin Periodontol. 2002;29(3):197-212.

26. Esposito M, Hirsch JM, Lekholm U, Thomsen P. Biological factors contributing to failures of osseointegrated oral implants. (II). Etiopathogenesis. Eur J Oral Sci. 1998;106(3):721-64.

27. Snauwaert K, Duyck J, Steenberghe D, Quirynen M, Naert I. Time dependent failure rate and marginal bone loss of implant supported prostheses: a 15-year follow-up study. Clin Oral Investig. 2000;4(1):13-20.

28. Tonetti MS. Risk factors for osseodisintegration. Periodontol 2000. 1998;17:55-62.

29. Quirynen M, Teughels W. Microbiologically compromised patients and impact on oral implants. Periodontol 2000. 2003;33:119-28.

30. Mombelli A, Lang NP. The diagnosis and treatment of peri-implantitis. Periodontol 2000. 1998;17:63-76.

31. Mayfield LJ. Peri-implant diseases: diagnosis and risk indicators. J Clin Periodontol. 2008;35(8):292304.

32. Mombelli A, Müller N, Cionca N. The epidemiology of peri-implantitis. Clin Oral Implants Res. 2012;23(6):67-76.

33. Rashid H, Sheikh Z, Vohra F, Hanif A, Glogauer M. Peri-implantitis: A re-view of the disease and report of a case treated with allograft to achieve bone regeneration. Dent Open J. 2015;2(3):87-97.

34. Lang NP, Wilson TG, Corbet EF. Biological complications with dental implants: their prevention, diagnosis and treatment. Clin Oral Implants Res. 2000;11(1):146-55.

35. Georgiev O, Nogalchev $\hat{E}$. Local complications occurring during dental implantation. JIMAB. 2010;16(4):35-7.

36. Albrektsson $\mathrm{T}$, Isidor $\mathrm{F}$, Lang $\mathrm{N}$, Karring $\mathrm{T}$. Proceedings of the 1st European Workshop on Periodontology. Quintessence Publish; 1994.
37. Prathapachandran J, Suresh N. Management of periimplantitis. Dent Res J. 2012;9(5):516-21.

38. Longridge N, Clarke P, Aftab R, Ali T, Boursicot K, Sales D. Endodontics USP. Oxford, UK: Blackwell Munksgaard; 2001.

39. Tolman DE, Laney WR. Tissue-integrated prosthesis complications. Int $\mathbf{J}$ Oral Maxillofac Implants. 1992;7(4):477-84.

40. Gammage DD, Bowman AE, Meffert RM. Clinical management of failing dental implants: four case reports. J Oral Implantol. 1989;15(2):124-31.

41. Katona TR, Goodacre CJ, Brown DT, Roberts WE. Force-moment systems on single maxillary anterior implants: effects of incisal guidance, fixture orientation, and loss of bone support. Int $\mathrm{J}$ Oral Maxillofac Implants. 1993;8(5):512-22.

42. Rieger MR, Mayberry M, Brose MO. Finite element analysis of six endosseous implants. J Prosthet Dent. 1990;63(6):671-6.

43. Abrahams JJ. Dental CT imaging: a look at the jaw. Radiology. 2001;219(2):334-45.

44. Weinberg LA, Kruger B. A comparison of implant/prosthesis loading with four clinical variables. Int J Prosthodont. 1995;8(5):421-33.

45. Liaw K, Delfini RH, Abrahams JJ. Dental Implant Complications. Semin Ultrasound CT MR. 2015;36(5):427-33.

46. Goodacre CJ, Bernal G, Rungcharassaeng K, Kan JY. Clinical complications with implants and implant prostheses. J Prosthet Dent. 2003;90(2):121-32.

47. Balshi TJ, Hernandez RE, Pryszlak MC, Rangert B. A comparative study of one implant versus two replacing a single molar. Int $\mathbf{J}$ Oral Maxillofac Implants. 1996;11(3):372-8.

48. Jemt T. Single implants in the anterior maxilla after 15 years of follow-up: comparison with central implants in the edentulous maxilla. Int J Prosthodont. 2008;21(5):400-8.

49. Haas R, Pouilly N, Mailath G, Watzek G. Brånemark single tooth implants: a preliminary report of 76 implants. J Prosthet Dent. 1995;73(3):274-9.

50. Pjetursson BE, Asgeirsson AG, Zwahlen M, Sailer I. Improvements in implant dentistry over the last decade: comparison of survival and complication rates in older and newer publications. Int $\mathbf{J}$ Oral Maxillofac Implants. 2014;29:308-24.

Cite this article as: Bukhari MA, Almalki NG, Alkhudhayr AM, Alburaiki SZ, Aljumaiah AZ, Haddad SK, et al. Mechanical, technical, and biological complications of dental implants. Int J Community Med Public Health 2022;9:476-80. 